\title{
Intraoperative pulmonary flow study for decision making in the comprehensive stage II hybrid procedure
}

\author{
Matteo Trezzi, MD, ${ }^{\mathrm{a}}$ Varsha M. Bandisode, MD, ${ }^{\mathrm{b}}$ Minoo N. Kavarana, MD, ${ }^{\mathrm{a}}$ and Scott M. Bradley, MD, ${ }^{\mathrm{a}}$ \\ Charleston, SC
}

The comprehensive stage II hybrid procedure includes aortic arch reconstruction, removal of pulmonary artery bands, and creation of a bidirectional superior cavopulmonary connection (BSCC) ${ }^{1,2}$ Success of the stage II procedure is dependent on adequate protection of the pulmonary vascular bed by the branch pulmonary artery bands. Inadequate protection can result in poor candidacy for or

\footnotetext{
From the Divisions of Pediatric Cardiac Surgery ${ }^{\mathrm{a}}$ and Pediatric Cardiology, ${ }^{\mathrm{b}}$ Medical University of South Carolina, Charleston, SC.

Disclosures: Authors have nothing to disclose with regard to commercial support.

Received for publication Feb 17, 2014; revisions received March 4, 2014; accepted for publication March 21, 2014; available ahead of print April 17, 2014.

Address for reprints: Scott M. Bradley, MD, Pediatric Cardiac Surgery, Medical University of South Carolina, CSB 424, 96 Jonathan Lucas St, Charleston, SC 29425

(E-mail: bradlesm@musc.edu).

J Thorac Cardiovasc Surg 2014;148:743-5

0022-5223/ $\$ 36.00$

Copyright (C) 2014 by The American Association for Thoracic Surgery

http://dx.doi.org/10.1016/j.jtcvs.2014.03.037
}

failure of the superior cavopulmonary connection. In such cases, pulmonary flow at stage II can be provided by a systemic-pulmonary shunt, rather than a BSCC. Candidacy for stage II palliation is generally assessed by cardiac catheterization. However, evaluation of the pulmonary resistance during catheterization may be inaccurate, leading to an incorrect decision regarding the source of pulmonary blood flow at stage II palliation. We propose the use of an intraoperative pulmonary flow study as an alternative method of evaluating the adequacy of the pulmonary vascular bed in this setting. The technique was introduced by Frank Hanley for use during pulmonary artery unifocalization and can guide intraoperative decision making when preoperative studies of the pulmonary bed are difficult or inadequate. ${ }^{3,4}$

\section{CLINICAL SUMMARY}

Success of a BSCC is dependent on the pulmonary vascular bed being able to accept superior vena caval flow

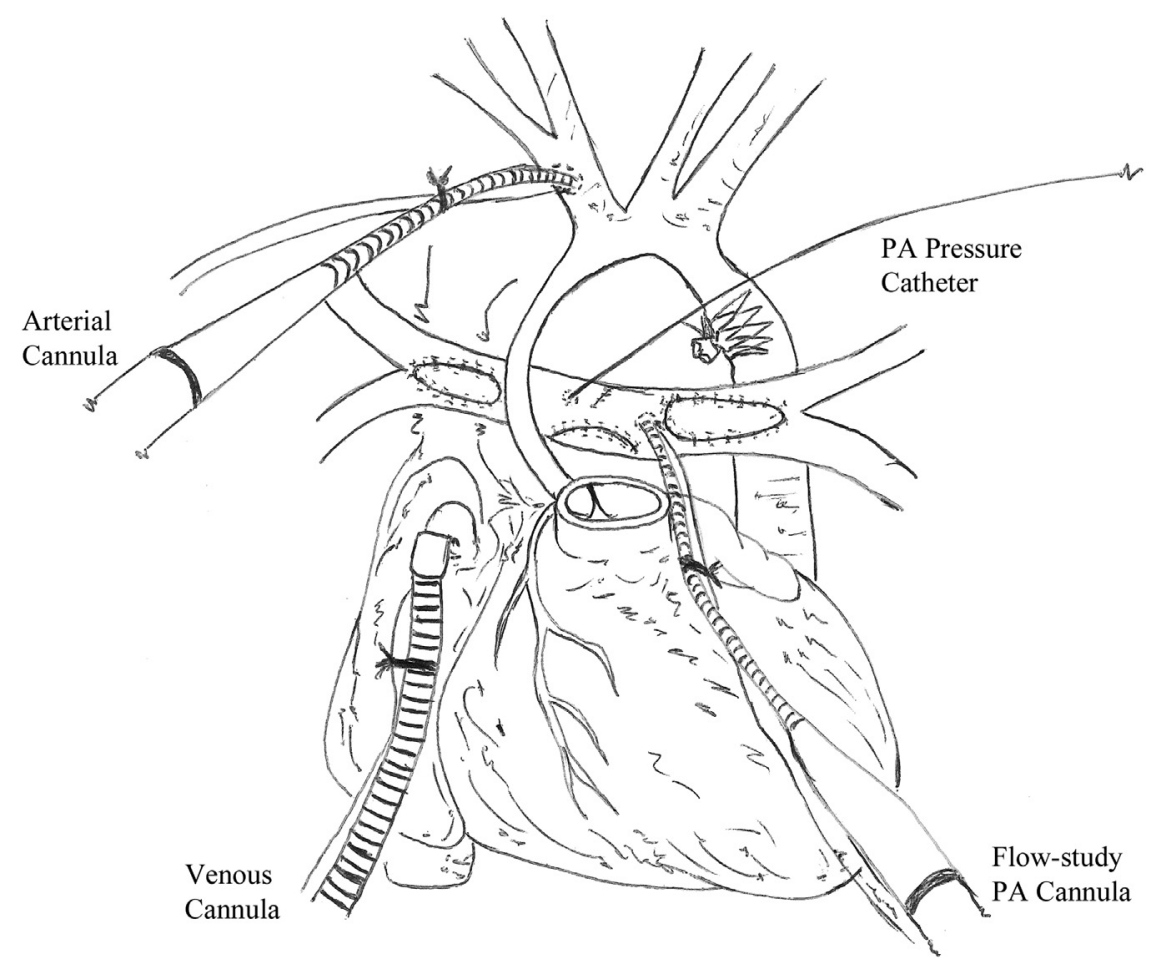

FIGURE 1. Intraoperative pulmonary flow study during comprehensive stage II hybrid procedure. The pulmonary arteries have been isolated and reconstructed by dividing the stented ductus with temporary occlusion of the aortic end, dividing the main pulmonary artery with patch closure of the distal end, removing the branch pulmonary bands, and patch-augmenting the band sites. PA, Pulmonary artery. 
TABLE 1. Cardiac catheterization pressure measurements

\begin{tabular}{lccccc}
\hline Patient & Age (mo) & RPA pressure $(\mathbf{m m ~ H g})$ & LPA pressure $(\mathbf{m m}$ Hg) & LA pressure (mm Hg) & Estimated PVR (Wood units) \\
\hline 1 & 6.0 & $22^{*}$ & $35^{*}$ & 7 & 7.2 \\
1 & 7.4 & 14 & 41 & 9 & 3.4 \\
1 & 14.0 (post-stage II) & $17^{*}$ & $22^{*}$ & 8 & 2.0 \\
2 & 5.4 & $20^{*}$ & $26^{*}$ & 6 & 4.6 \\
\hline
\end{tabular}

$L A$, Left atrial; $L P A$, left pulmonary artery; $P V R$, pulmonary vascular resistance; $R P A$, right pulmonary artery. *Pulmonary vein wedge pressure.

(approximately one half of systemic venous flow) with a transpulmonary pressure gradient of $15 \mathrm{~mm} \mathrm{Hg}$ or less. A pulmonary flow study was designed to assess this criterion. After repeat sternotomy and mediastinal dissection, cardiopulmonary bypass is established with an arterial cannula in the innominate artery and a single venous drainage cannula in the right atrium. The pulmonary arteries are isolated and reconstructed (Figure 1). A second arterial cannula and a pressure monitoring line are placed into the reconstructed pulmonary arteries. With the lungs ventilated and the heart decompressed, flow is gradually increased into the pulmonary arteries while systemic flow is maintained at 2.5 $\mathrm{L} / \mathrm{min} / \mathrm{m}^{2}$. The ability to achieve "one-half flow" $(\sim 1.25$ $\mathrm{L} / \mathrm{min} / \mathrm{m}^{2}$ ) into the pulmonary bed at a mean pressure of $15 \mathrm{~mm} \mathrm{Hg}$ or less is used as an indicator of acceptability for a BSCC.

\section{RESULTS}

Patient 1 was born at 31 weeks gestation, weighing 1.6 $\mathrm{kg}$, with a double-inlet left ventricle, hypoplasia of the left atrioventricular valve, ventriculoarterial discordance, aortic arch hypoplasia and coarctation, and a mildly restrictive atrial septal defect. She initially underwent bilateral branch pulmonary artery banding, ductal stenting, and balloon atrial septostomy. Cardiac catheterization at 6 months of age showed elevated pulmonary vein wedge pressures (Table 1). Treatment with sildenafil was initiated. Repeat catheterization 6 weeks later continued to show elevated left branch pulmonary artery pressure (Table 1). At 8 months of age, she underwent second-stage palliation. An intraoperative pulmonary flow study was performed. At a flow equal to $3 / 8$ systemic, the mean pulmonary artery pressure reached $15 \mathrm{~mm} \mathrm{Hg}$. On the basis of this finding, the decision was made to use a systemic to pulmonary shunt (5-mm central shunt) along with the Norwood procedure. The patient was discharged with systemic oxygen saturations of $75 \%$ to $82 \%$. Cardiac catheterization at 6 months post-stage II showed low pulmonary vascular resistance (Table 1); she subsequently underwent successful BSCC.

Patient 2 was born at 36 weeks gestation, weighing 2.5 $\mathrm{kg}$, with hypoplastic left heart syndrome (aortic atresia, mitral stenosis) and evidence of left ventricular to coronary artery fistulae. He underwent bilateral branch pulmonary artery banding and ductal stenting. Cardiac catheterization at 5 months of age showed elevated pulmonary vein wedge pressures (Table 1). Treatment with sildenafil was initiated. At 7 months of age, he underwent second-stage palliation. During an intraoperative pulmonary flow study, at a flow equal to $1 / 2$ systemic, the mean pulmonary artery pressure reached $12 \mathrm{~mm} \mathrm{Hg}$. The decision was made to proceed with a BSCC along with the Norwood procedure. The patient did well and was discharged with systemic oxygen saturations of $78 \%$ to $84 \%$.

\section{DISCUSSION}

Candidacy for comprehensive stage II hybrid palliation is typically assessed by cardiac catheterization. However, evaluation of the pulmonary resistance during catheterization may be difficult for several reasons. The pressure measured in the branch pulmonary arteries by an antegrade catheter can be dampened because of the narrow lumen at the branch pulmonary artery band site. Alternative approaches to pressure measurement include the use of a pressure guidewire ${ }^{5}$ or pulmonary vein wedge pressures. Accurate determination of pulmonary vascular resistance also requires determining the relative flows to the 2 lungs. In the setting of individual branch pulmonary artery bands, flow to the 2 lungs often is uneven, and determination of relative flows may not be possible.

\section{CONCLUSIONS}

Inaccurate evaluation of pulmonary vascular resistance may lead to an incorrect decision regarding the source of pulmonary blood flow at the time of stage II palliation. An incorrect decision to perform BSCC can result in elevated superior vena caval pressure, cyanosis, and the need for BSCC takedown. ${ }^{2,6}$ On the other hand, an incorrect decision to use a systemic-pulmonary shunt results in ongoing parallel circulation with volume loading of the ventricle, pressure-dependent pulmonary flow, and potential hemodynamic instability that can follow a stage I Norwood procedure. In one recent report, the only 2 hospital deaths after the stage II hybrid procedure involved BSCC takedown. ${ }^{2}$ We propose the intraoperative pulmonary flow study as a useful method of evaluating the adequacy of the pulmonary vascular bed in this setting. The flow study was successfully used to select the source of pulmonary blood flow in 2 patients in whom the pre-stage II catheterization yielded equivocal results. 


\section{References}

1. Galantowicz M, Cheatham JP, Phillips A, Cua CL, Hoffman TM, Hill SL, et al. Hybrid approach for hypoplastic left heart syndrome: intermediate results after the learning curve. Ann Thorac Surg. 2008;85:2063-71.

2. Baba K, Kotani Y, Chetan D, Chaturvedi RR, Lee K, Benson LN, et al. Hybrid versus Norwood strategies for single-ventricle palliation. Circulation. 2012;126: S123-31.

3. Reddy VM, Petrossian E, McElhinney DB, Moore P, Teitel DF, Hanley FL. One-stage complete unifocalization in infants: when should the ventricular septal defect be closed? J Thorac Cardiovasc Surg. 1997; 113:858-68
4. Malhotra SP, Hanley FL. Surgical management of pulmonary atresia with ventricular septal defect and major aortopulmonary collaterals: a protocol-based approach. Semin Thorac Cardiovasc Surg Pediatr Card Surg Ann. 2009;12: $145-51$

5. Zampi JD, Hirsch JC, Goldstein BH, Armstrong AK. Use of a pressure guidewire to assess pulmonary artery band adequacy in the hybrid stage I procedure for highrisk neonates with hypoplastic left heart syndrome and variants. Congenit Heart Dis. 2013:8:149-58.

6. Pizarro C, Murdison KA, Derby CD, Radtke W. Stage II reconstruction after hybrid palliation for high-risk patients with a single ventricle. Ann Thorac Surg. 2008:85:1382-8.

\section{Use of polytetrafluoroethylene vascular graft to cover the kinking protector of left ventricular assist device facilitates later pump exchange}

Evgenij V. Potapov, MD, PhD, Roland Hetzer, MD, PhD, and Thomas Krabatsch, MD, PhD, Berlin, Germany

The HeartWare left ventricular assist device (HVAD; HeartWare Inc, Framingham, Mass) is a reliable tool for the treatment of end-stage heart failure. To date, more than 5000 pumps have been implanted in patients worldwide with excellent clinical results, and the numbers are increasing every year. However, some patients require a pump exchange during support, mostly because of thrombosis and less frequently for cable damage. ${ }^{1}$ The surgical technique has been described. ${ }^{1,2}$ Dissecting the plastic rings of the kinking protector from the epicardium is a major surgical challenge during pump exchange because of severe epicardial adhesions and ingrowth of tissue between the plastic rings. This step is timeconsuming and may lead to bleeding or damage to the right ventricle. There is only one way to avoid this risk-by not dissecting the kinking protector from the heart surface. One possibility is to resect only the upper parts of the first 7 to 8 plastic rings, because these upper parts are not attached to the epicardium, and then to remove the graft from the kinking protector. The disadvantage of this approach is that unless a new kinking protector is attached after pump exchange, the outflow graft remains partially unprotected. A more elegant option is to avoid adhesions around the

From the Deutsches Herzzentrum Berlin, Berlin, Germany.

Disclosures: Authors have nothing to disclose with regard to commercial support.

Received for publication Jan 13, 2014; accepted for publication March 21, 2014; available ahead of print April 24, 2014.

Address for reprints: Evgenij V. Potapov, MD, PhD, Deutsches Herzzentrum Berlin, Augustenburger Platz 1, 13353 Berlin, Germany (E-mail: potapov@dhzb.de).

J Thorac Cardiovasc Surg 2014;148:745-6

$0022-5223 / \$ 36.00$

Copyright (c) 2014 by The American Association for Thoracic Surgery

http://dx.doi.org/10.1016/j.jtcvs.2014.03.034

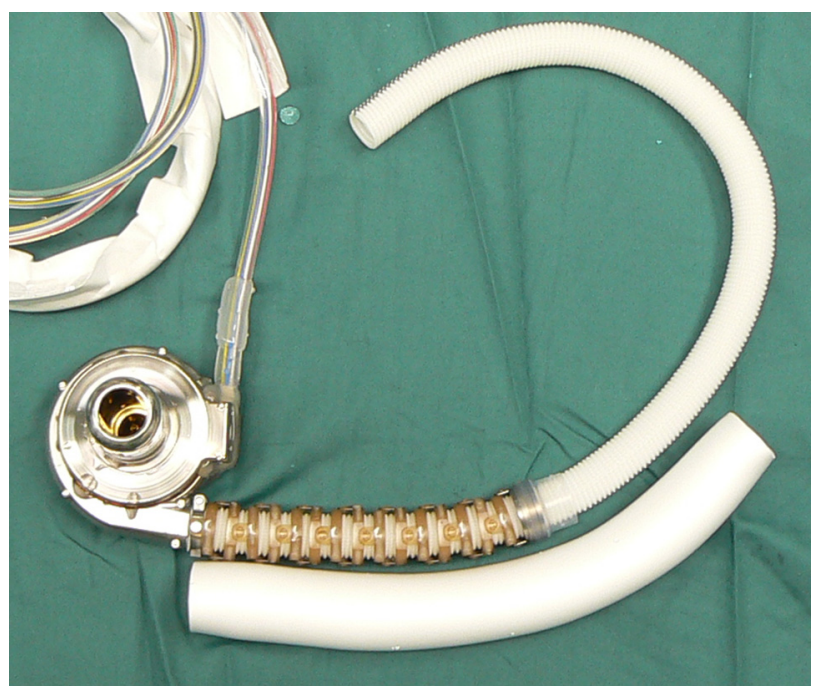

FIGURE 1. Assembled HeartWare HVAD (HeartWare Inc, Framingham, Mass) and the polytetrafluoroethylene (Gore-Tex; WL Gore \& Associates, Inc, Newark, Del) graft (diameter $20 \mathrm{~mm}$ ) before it is pulled over the kinking protector of the HeartWare HVAD.

kinking protector altogether by pulling a $20-\mathrm{mm}$ diameter polytetrafluoroethylene (Gore-Tex; WL Gore \& Associates, Inc, Newark, Del) graft over the kinking protector before implantation of the pump (Figures 1 and 2). To avoid migration of the polytetrafluoroethylene (Gore-Tex) graft, we attach it to the pump housing or the first plastic ring of the kinking protector using 3-0 Prolene suture. In addition, so that it can be easily identified, the fixation screw is covered with a silicon tube ( $1 \mathrm{~mm}$ diameter, $2 \mathrm{~cm}$ long) usually used to cover the branches of a mosquito clamp.

During pump exchange, the surrounding graft should be opened and the kinking protector within the outflow graft 